\title{
Influence of humic preparations on the content of carbohydrates in structural units and their water resistance
}

\author{
Vladimir Lykhman $^{1,}{ }^{,}$, Alexander Klimenko ${ }^{1}$, Marina Dubinina ${ }^{1}$, Olga $\mathrm{Naimi}^{1}$, and Elena \\ Polienko ${ }^{1}$ \\ ${ }^{1}$ Federal State agrarian research center of Rostov, 346735, 1 Institutskaya street, village Rassvet, \\ Aksay district, Rostov region, Russia
}

\begin{abstract}
The effect of the combined use of humic preparations and pesticides in various dosages on the quantitative composition of carbohydrates in agronomically valuable soil aggregates was studied. Biologically active humic substances indirectly, through plants and microorganisms, intensify the release of sugars, which play an essential role in the initial stages of the soil aggregates formation. Pesticides have a depressing effect on the soil microflora development, which, in turn, is one of the factors of the agronomically valuable soil structure formation. The introduction of humic preparations reduces the toxic effect of pesticides and reduces seasonal deterioration in the structural state of the soil. It has been shown that the distribution of aggregates according to variants, both in the case of dry sieving and in the case of wet sieving, correlates with the dynamics of the carbohydrate content in soil particles. This tendency is especially perceptible in the variants where pesticides were introduced into the soil together with the humic preparation. The correlation between the distribution of soil aggregates and carbohydrates according to Chaddock's scale is salient $(\mathrm{r}=0.532)$. The introduction of humic preparations makes it possible to reduce the loss of the agronomically valuable structure even in aftereffect.
\end{abstract}

\section{Introduction}

The use of chemical agents in agricultural technology, in addition to mechanized and automated systems, is a required element of intensive agriculture. However, if fertilizers compensate for the lack of soil fertility elements, and pesticides reduce the negative impact of biological objects, then restoration, regulation and formation of the soil structure is a longer and more laborious process. It is associated with a change and redistribution of the mechanical load on cultivated soils, the formation of rhizosphere microbiological communities in the soil, the accumulation and distribution of soil moisture, and soil gas exchange [1-2]. Important factors in this context are the weather conditions, such as high temperatures, low atmospheric humidity and a low amount of precipitation, as a result of

\footnotetext{
* Corresponding author: lykvladimir@yandex.ru
} 
which the prerequisites for erosion processes are created, the formation and development of the root mass of plants, and with it the rhizosphere communities, is inhibited. An important factor in this context are the weather conditions, such as high temperature, low air humidity, low precipitation, which leads to the emergence of erosion processes, as well as suppresses the formation and development of the plant root mass and the rhizosphere communities [3-4]. Consequently, microorganisms reduce the release of polysaccharides, the most important function of which in the soil is their participation in the soil structure formation [5-9].

Numerous studies have found that the introduction of polysaccharides of various nature into the soil positively affects the soil structure formation [10-11]. The direct correlation between the carbohydrate content and the degree of aggregation of soil particles has been repeatedly proved [12], while the remove of organic substances from the soil by chemical means negatively affects the quality of the soil aggregate state [13-14].

The scientific literature widely covers the adhesive ability of microbial mucus, which in turn is due to the presence of polysaccharides, aminosaccharides, and uronic acids [15]. It should be noted that the aggregating ability of bacterial secretions is more pronounced than the root secretions of plants. However, legumes are an exception in this case, since their roots contain more pectin than the roots of cereal, and therefore legumes are highly effective for improving the agrophysical qualities of the soil. In water-resistant soil aggregates with a low total carbon content (up to $1 \%$ ), predominantly polysaccharides were found.

The adhesive properties of polysaccharides are due to a number of conditions:

- linear structure of molecules;

- such a spatial orientation of the molecules, in which conditions for the emergence of Van der Waals forces are created;

- a large number of $\mathrm{OH}$ groups capable of forming hydrogen bonds;

- the presence of acidic $\mathrm{COOH}$ groups, which can carry out ionic interactions by means of 2- and 3 -valent cations.

\section{Materials and research methods}

Field experiments were carried out in Aksay district of the Rostov region. The climate of this region is arid, moderately hot, continental. Relative humidity has a pronounced annual course. Its smallest values are observed in July (50-60\%), the minimum on some days can be $25-30 \%$ or lower.

The average long-term amount of rainfall is $492 \mathrm{~mm}$; their distribution according to an agronomic estimate is often unfavorable. The accumulation of moisture in the soil begins mainly in late October - November, and its maximum reserve is noted in early spring (from mid-March to early April). During the spring-summer period of 2015, $278.5 \mathrm{~mm}$ of rain fell, 2017 - $221.6 \mathrm{~mm}, 2018$ - $135 \mathrm{~mm}$ (Figure 1). 


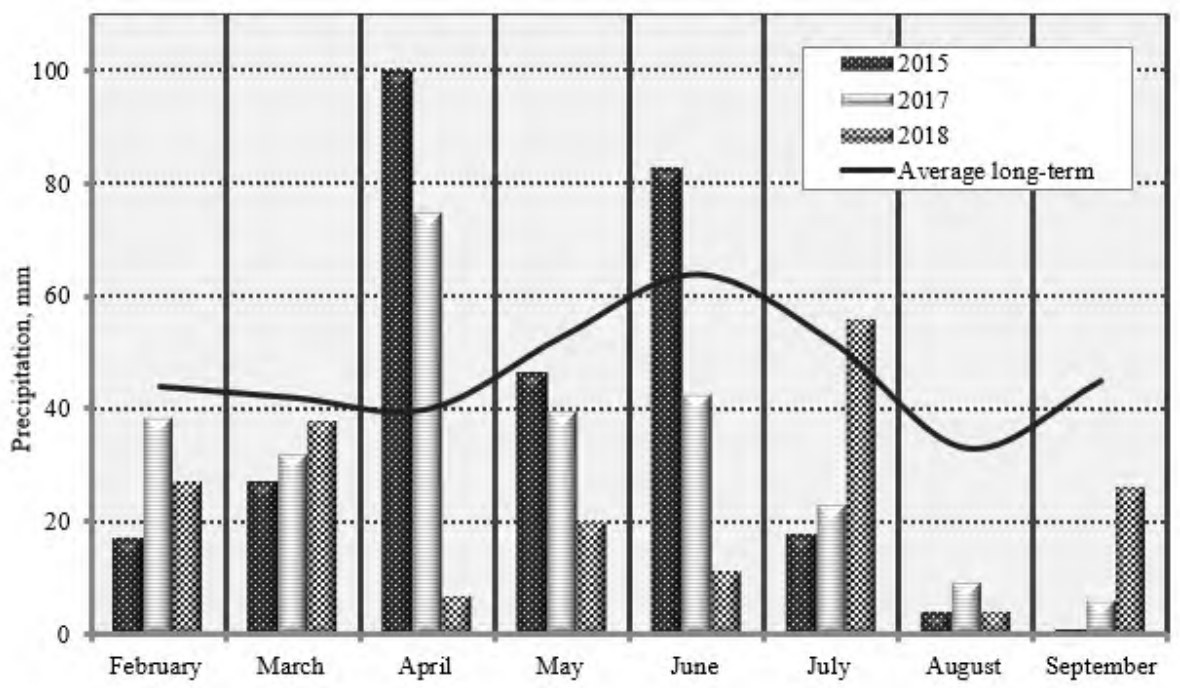

Fig. 1. Distribution of rainfall in the spring-summer period of vegetation of winter wheat in the years of research

Rostov region is a zone of risky agriculture due to possible drought. However, the years 2015 and 2017 are characterized by relatively optimal hydration; the hydrothermal coefficient (HTC) for the spring-summer growing season was 1.43 and 1.11, respectively. Extremely arid conditions were in 2018: the HTC was abnormally low (0.2), which affected the yield of winter wheat, it amounted to an average of $23 \mathrm{~kg} / \mathrm{ha}$ (table 1).

Table 1. Distribution of rainfall during the growing season winter wheat $(2015,2017,2018$ years)

\begin{tabular}{|l|c|c|c|c|c|c|}
\hline \multirow{2}{*}{ Index } & \multicolumn{7}{c|}{ Month } & \multirow{2}{*}{$\begin{array}{c}\text { Per } \\
\text { season }\end{array}$} & \multirow{2}{*}{ April - June } \\
\cline { 2 - 6 } & april & may & june & july & \\
\hline \multicolumn{7}{|c|}{$\mathbf{2 0 1 5}$} \\
\hline Sum of air temperatures, ${ }^{\circ} \mathrm{C}$ & 309.0 & 607.6 & 681.0 & 753.3 & 3740.5 & 1597.6 \\
\hline Sum of rainfall, mm & 100.0 & 46.5 & 83.0 & 17.8 & 252.2 & 229.5 \\
\hline HTC & 3.23 & 0.76 & 1.21 & 0.23 & 0.67 & 1.43 \\
\hline \multicolumn{7}{|c|}{$\mathbf{2 0 1 7}$} \\
\hline Sum of air temperatures, ${ }^{\circ} \mathrm{C}$ & 291.0 & 489.8 & 627.0 & 737.8 & 3521.4 & 1407.8 \\
\hline Sum of rainfall, mm & 74.8 & 39.6 & 42.6 & 23.2 & 195.4 & 157.0 \\
\hline HTC & 2.57 & 0.8 & 0.67 & 0.31 & 0.55 & 1.11 \\
\hline \multicolumn{7}{|c|}{$\mathbf{2 0 1 8}$} \\
\hline Sum of air temperatures, ${ }^{\circ} \mathrm{C}$ & 417.0 & 601.4 & 717.0 & 796.7 & 3879.1 & 1735.4 \\
\hline Sum of rainfall, mm & 5.5 & 27.0 & 3.0 & 90.0 & 223.5 & 35.5 \\
\hline HTC & 0.13 & 0.45 & 0.04 & 1.13 & 0.58 & 0.20 \\
\hline
\end{tabular}

Soil sampling was carried out according to state standard 28168-89, assessment of the structural state of the soil - according to state standard 12536-79. The method of dry and wet sieving according to N. I. Savinov was used to determine the soil structure. The structural and water strength factors of soil aggregates were also calculated. Carbohydrates were determined using the phenol sulfate method Dubois in fractions $3-5,2-3,1-2 \mathrm{~mm}$, which account for up to $40 \%$ of all aggregates and up to $80 \%$ of agronomically valuable units in the studied chernozem. Here are the results for a fraction of 3-5 $\mathrm{mm}$, characterized 
by a fairly high water resistance of the aggregates. MS Excel program was used when building diagrams.

The experimental design is shown in table 2. The field experiment was laid in 3 -fold repetition, the plot area was $864 \mathrm{~m}^{2}$. Before sowing, seeds were treated with Alto-Super fungicide in dosage of $0.451 /$ ha in all variants. The treatment of crops with the herbicide tank mixture (herbicide + humic preparation) and with the humic preparation BIO-Don was carried out once in the tillering phase. Soil samples were taken from the arable layer in the following periods: seedling phase, tillering phase (before treatment with a humic preparation and herbicide), tillering phase (14 days after treatment with a humic preparation and herbicide) and at the time of harvesting winter wheat.

Table 2. Experimental Design

\begin{tabular}{|c|c|c|}
\hline Variant & Herbicide & BIO-Don \\
\hline 1 Background $1\left(\mathrm{NH}_{4} \mathrm{NO}_{3} 100 \mathrm{~kg} / \mathrm{ha}\right)$ & - & - \\
\hline 2 Background $1+$ herbicide rate 1 & Granstar Pro $10 \mathrm{~g} / \mathrm{ha}$ & - \\
\hline 3 Background $1+$ herbicide rate 2 & Granstar Pro $15 \mathrm{~g} / \mathrm{ha}$ & - \\
\hline 4 Background $1+$ herbicide rate 3 & Granstar Pro $20 \mathrm{~g} / \mathrm{ha}$ & - \\
\hline 5 Background $1+$ herbicide rate 4 & Granstar Pro $25 \mathrm{~g} / \mathrm{ha}$ & - \\
\hline 6 Background 2 (Background 1 + BIO-Don) & - & 1 \\
\hline 7 Background $2+$ herbicide rate 1 & Granstar Pro $10 \mathrm{~g} / \mathrm{ha}$ & 1 \\
\hline 8 Background $2+$ herbicide rate 2 & Granstar Pro $15 \mathrm{~g} / \mathrm{ha}$ & 1 \\
\hline 9 Background $2+$ herbicide rate 3 & Granstar Pro $20 \mathrm{~g} / \mathrm{ha}$ & 1 \\
\hline 10 Background $2+$ herbicide rate 4 & Granstar Pro $25 \mathrm{~g} / \mathrm{ha}$ & 1 \\
\hline
\end{tabular}

\section{Results and discussion}

Table 3 presents the calculation data for the structural coefficient in ordinary carbonate chernozem when treated with a humic preparation for the growing season 2017-2018.

Table 3. The value of the structural coefficient in ordinary carbonate chernozem

\begin{tabular}{|c|c|c|c|c|c|c|c|c|c|c|}
\hline \multirow{2}{*}{ Sampling Date } & \multicolumn{10}{|c|}{ Variant of experiment } \\
\cline { 2 - 12 } & $\mathbf{1}$ & $\mathbf{2}$ & $\mathbf{3}$ & $\mathbf{4}$ & $\mathbf{5}$ & $\mathbf{6}$ & $\mathbf{7}$ & $\mathbf{8}$ & $\mathbf{9}$ & $\mathbf{1 0}$ \\
\hline 20.10 .2017 & 1.36 & 3.57 & 2.55 & 1.98 & 2.21 & 2.78 & 3.09 & 4.66 & 3.22 & 3.83 \\
\hline 05.04 .2018 & 3.92 & 5.04 & 4.20 & 4.89 & 3.94 & 2.81 & 3.61 & 5.26 & 4.82 & 4.44 \\
\hline & & & & & & & & & & \\
\hline 25.05 .2018 & 4.72 & 4.93 & 4.89 & 5.11 & 6.40 & 6.04 & 6.20 & 4.87 & 4.35 & 4.54 \\
\hline 12.07 .2018 & 4.53 & 4.62 & 5.46 & 3.07 & 2.73 & 3.23 & 3.08 & 2.81 & 3.01 & 3.05 \\
\hline
\end{tabular}

In previous years, the dynamics of the structure state was similar. According to the obtained data, there is a positive dynamic of the structural coefficient after treatment of soil and germinated plants with a humic preparation together with herbicide (Figure 2). 


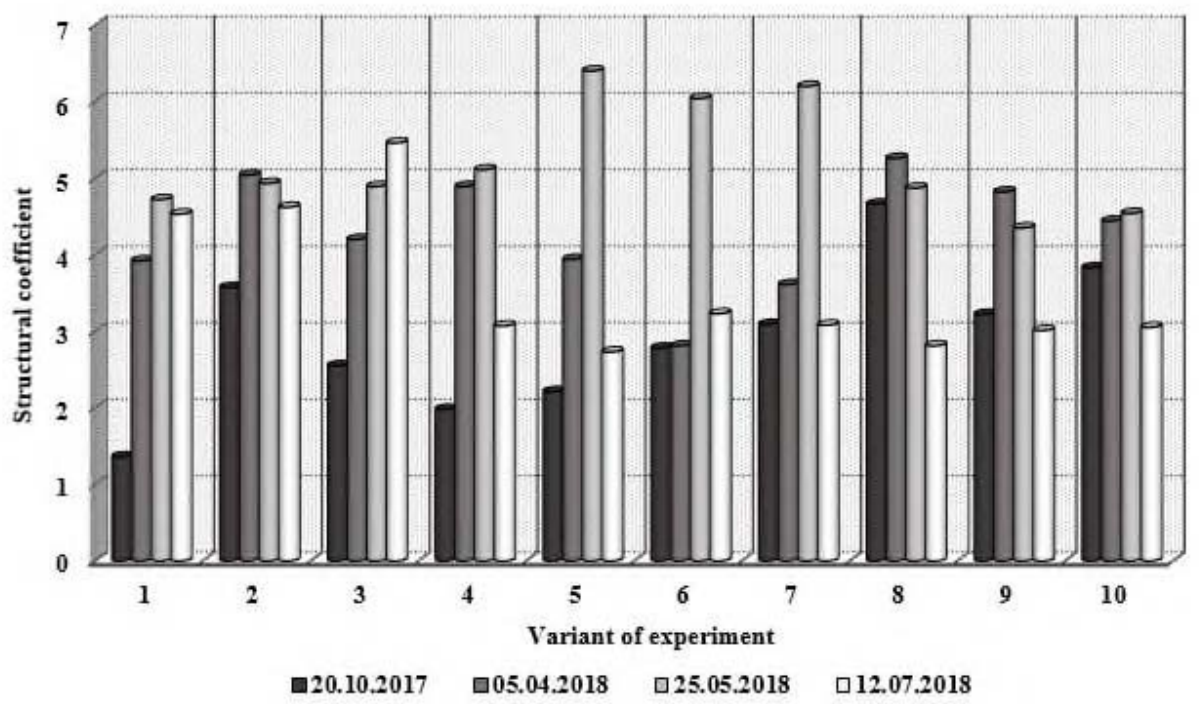

Fig. 2. Dynamics of the structural coefficient during the growing season 2017-2018.

However, in all cases, differences with the background are not significant $\left(\mathrm{SSD}_{0.05}=\right.$ 2.12). Probably, the leveling effect of mechanical processing by agricultural implements, the same in all cases, affected [16].

As a trend, a decrease in the effectiveness of the humic preparation due to the action of high concentrations of the herbicide is observed. So, in soil samples taken on July 12, 2018, in variants 4 and 5, in which Granstar Pro doses of 20 and $25 \mathrm{~g} /$ ha were used, the structural coefficient decreased by 1.46 and 1.80 , respectively. In variants where the treatment was carried out with a tank mixture, the dynamics are similar. The exception was variants 6 (background 2) and 7 (treatment with a tank mixture with a minimum dose of herbicide). The deterioration of the structural state of the soil in these variants during the growing season is insignificant, and when compared with the background, there is a noticeable increase in the structural coefficient by 1.50 and 1.55 , respectively, which is significantly more than in variants 2 and 3 with a minimum concentration of herbicide $(0.09$ and 0.093). A similar trend is manifested in the dynamics of the content of water-resistant aggregates (Figure 3). 


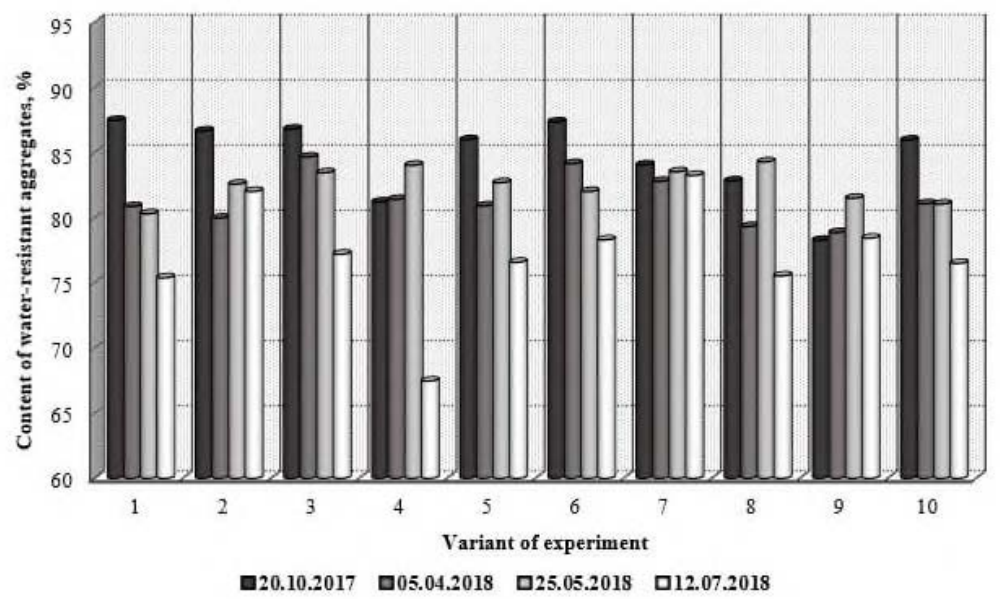

Fig. 3. The content of water-resistant aggregates in ordinary carbonate chernozem

As in the case with the structural coefficient, a decrease in the percentage of waterresistant aggregates is observed at the time of harvesting in all variants due to the influence of anthropogenic, biogenic and abiogenic factors. At the same time, the combined use of herbicide and humic preparation reduces the loss of water-resistant aggregates, and the introduction of a humic preparation without chemicals (background 2) allows to increase the water resistance of the aggregates. The number of water-resistant units increased by $7.85 \%$, while against the background this indicator decreased from 80.29 to $75.38 \%$.

One of the reasons for this trend is the maintenance of the total carbohydrates level in the soil due to plants root excretion and decomposition of plant residues by cellulosedestroying microorganisms [17]. Numerous studies have established that humic preparations can positively affect the soil microbiological activity, which means that they indirectly participate in the formation of an agronomically valuable structure $[10,18,19]$. In the presented graphs (Figures 4 and 5) there is a salient relationship between the distribution of some fractions and the total amount of carbohydrates according to Chaddock's scale $(r=0.532)$. From the data of Figures 4 and 5 it is seen that the content of aggregates of the 3-5 mm fraction correlates with the carbohydrate pool both in the case of dry sieving and in the case of wet sieving. This tendency is especially noticeable in variants $7-9$, in which a humic preparation was applied to the soil together with a herbicide at a dose of $10-20 \mathrm{~g} / \mathrm{ha}$. 


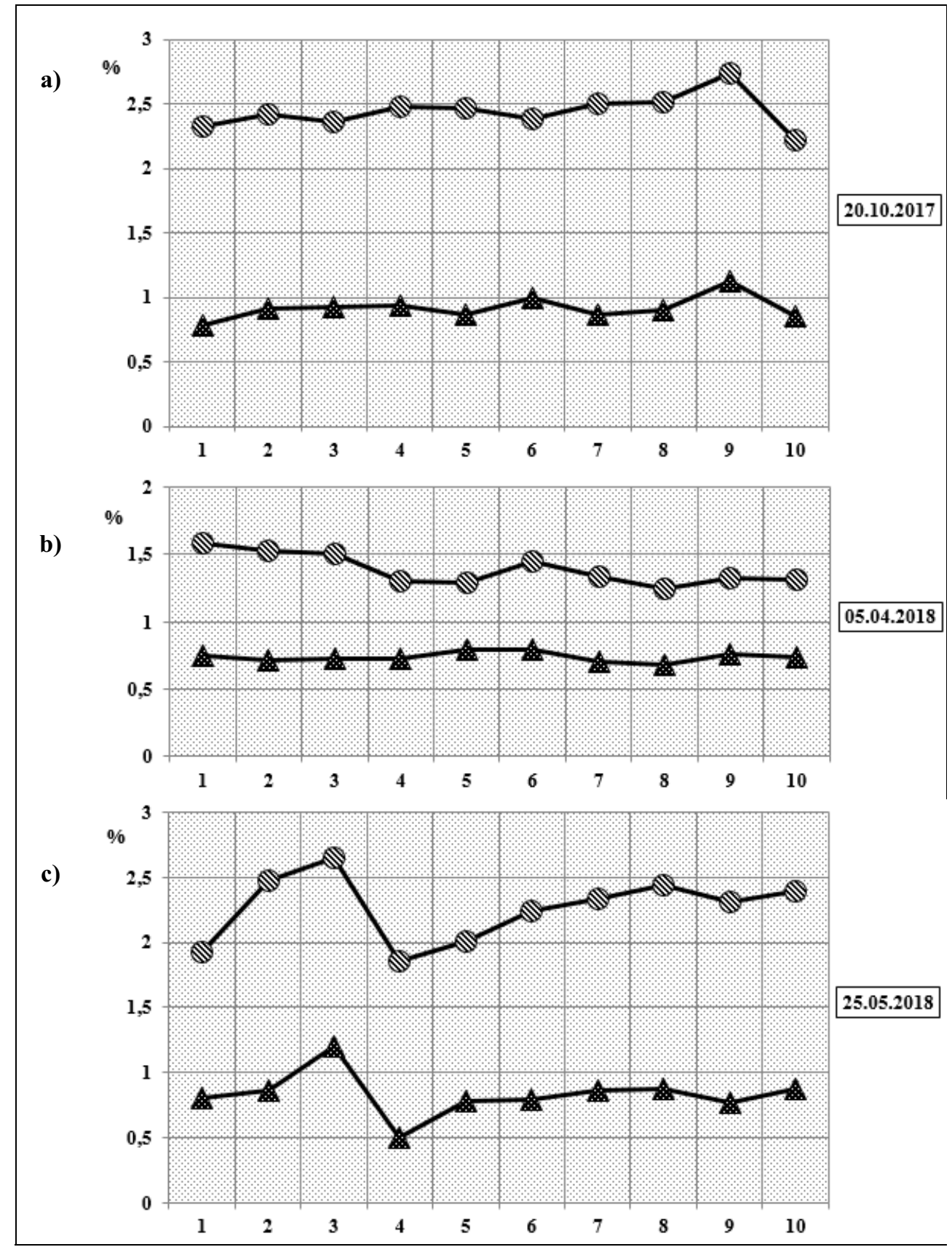




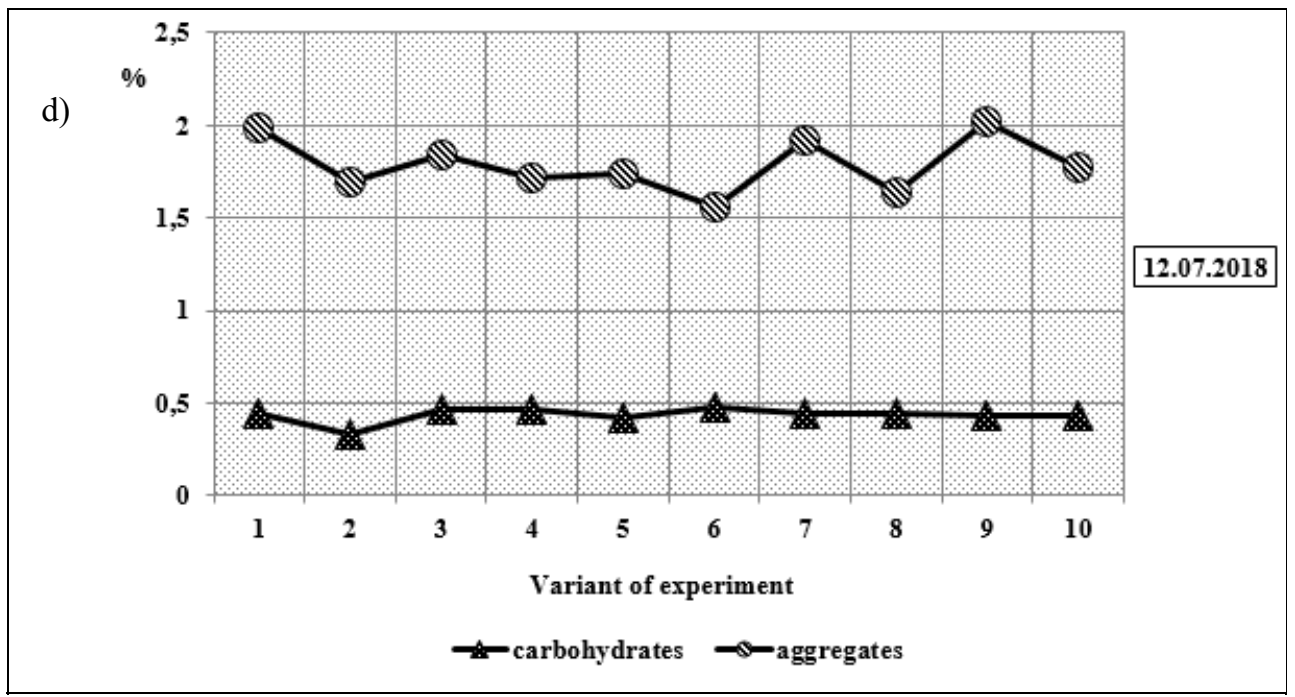

Fig. 4. The content of carbohydrates and aggregates fractions of 3-5 $\mathrm{mm}$ according to the results of dry sieving: a) 20.10.2017; b) 05.04.2018; c) 25.05.2018; d) 12.07.2018

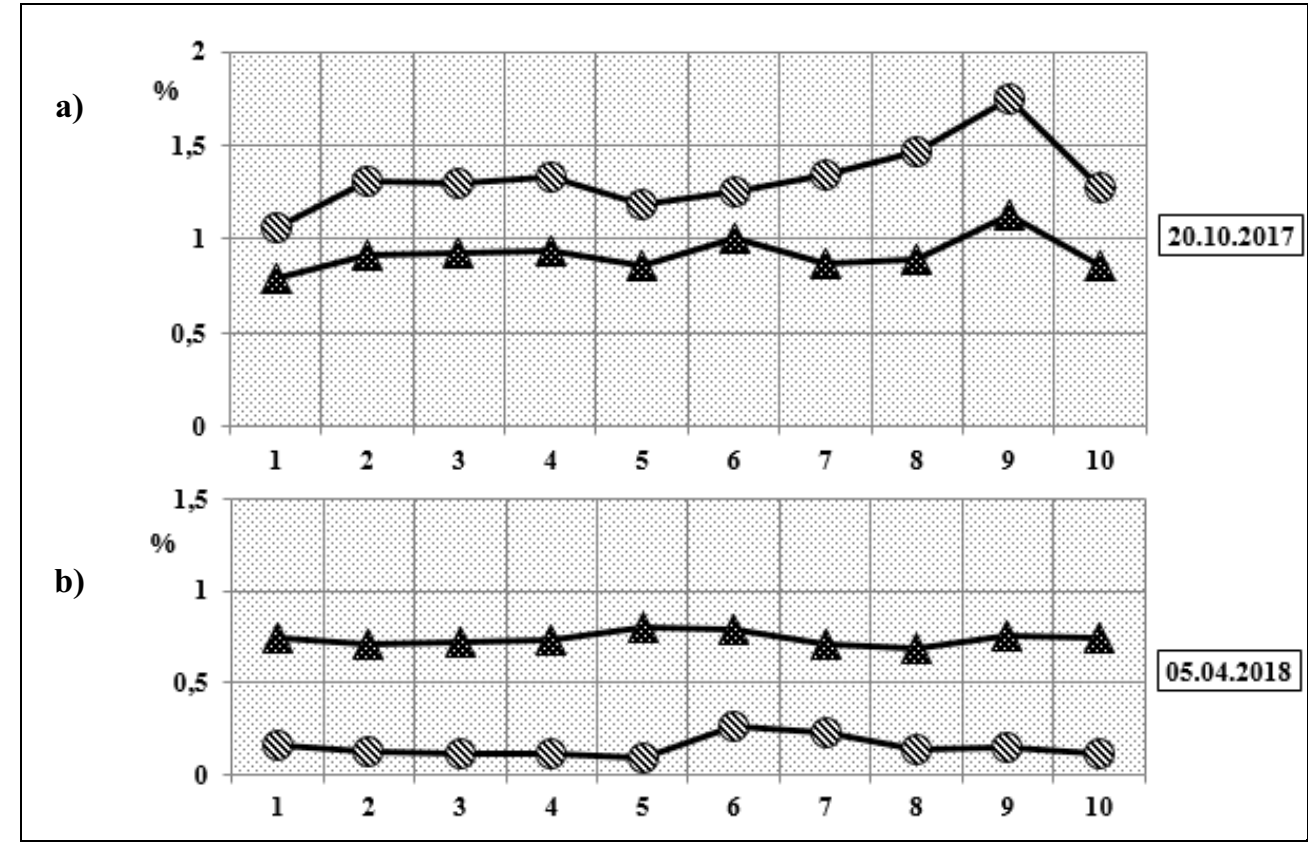




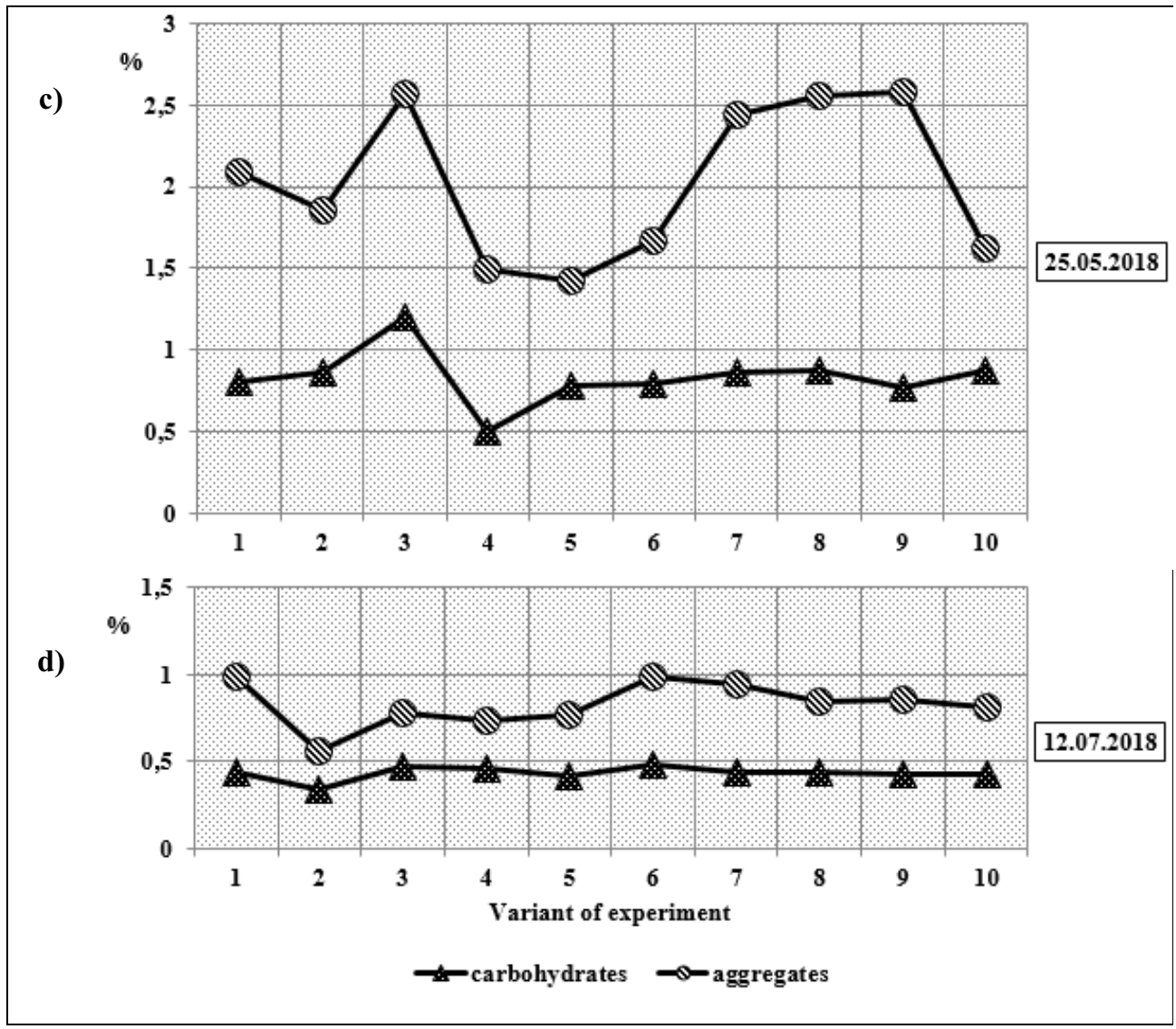

Fig. 5. The content of carbohydrates and aggregates of a fraction of 3-5 $\mathrm{mm}$ according to the results of wet sieving: a) 20.10.2017; b) 05.04.2018; c) 25.05.2018; d) 12.07 .2018

Since humic preparations are biologically active substances, they indirectly, through plant and microbiological communities, intensify the release of sugars. Carbohydrates probably play a significant role in the initial stages of the formation of soil aggregates; later, other organic substances predominate. The formation of water-resistant aggregates is explained by the action of humic substances released into the soil during sugars breakdown. Carbohydrates can form complex sols with aluminum and iron hydroxides [11]. Under the organic colloids' protection, sesquioxides and clay particles acquire the ability to move in the soil profile. The high chemical activity of carbohydrates in the interaction with metals, organic and inorganic colloids is determined by the linear structure of carbohydrate molecules, the presence of hydroxyl, carboxyl and amino groups.

The question of the mechanisms of interaction of carbohydrates with minerals remains open. The mechanism of binding of polysaccharide molecules to clay particles is explained by the presence of ionic and hydrogen bonds. Acid polysaccharides cannot have an ionic bond with a negatively charged clay like montmorillonite. The structuring effect of carbohydrates, especially sucrose, is due to the rapid biochemical decomposition of polysaccharides and its transformation into humic compounds. Apparently, these processes do occur when carbohydrates are added to the soil in order to study their structural effect. In our experiments, we studied soil carbohydrates, a significant part of which is associated with humus. Foliar treatment of vegetative plants with a biologically active substance 
provokes plants to produce root secretions, which in turn activates microorganisms of the rhizosphere and, as a result, an increase in the pool of carbohydrate components [20,21].

\section{Conclusions}

1. Pesticides, including herbicides and fungicides, due to their high toxicity to plant communities, indirectly cause degradation of the agrophysical properties of soils. This is evidenced by the decrease in the number of water-resistant aggregates in the variants with the herbicide treatment of winter wheat crops on the background of mineral fertilizer.

2. It was found that the correlation between the content of soil aggregates of 3-5 $\mathrm{mm}$ in size and carbohydrates is salient according to Chaddock's scale $(\mathrm{r}=0.532)$. This confirms the assumption of many authors about the structure-forming role of carbohydrates.

3. The introduction of humic preparations into the soil can reduce the seasonal deterioration of the structural state. With the cessation of the active substances intake, the value of the soil structural coefficient tends to its natural value (background).

\section{References}

1. Y. Dou, Y. Yang, S. An, Z. Zhu, Catena, Effects of different vegetation restoration measures on soil aggregate stability and erodibility on the Loess Plateau, China, 185, 104294 (2020) ISSN 0341-8162. https://doi.org/10.1016/j.catena.2019.104294

2. J. I. Rivera, C. A. Bonilla, Catena, Predicting soil aggregate stability using readily available soil properties and machine learning techniques, 187, 104408 (2020) ISSN 0341-8162. https://doi.org/10.1016/j.catena.2019.104408

3. A. A. Besalatpour, S. Ayoubi, M. A. Hajabbasi, M. R. Mosaddeghi, R. Schulin, Catena, Estimating wet soil aggregate stability from easily available properties in a highly mountainous watershed, 111, 72-79 (2013) ISSN 0341-8162. https://doi.org/10.1016/j.catena.2013.07.001

4. T. Mawodza, G. Burca, S. Casson, M. Menon, Geoderma, Wheat root system architecture and soil moisture distribution in an aggregated soil using neutron computed tomography, 359, $113988 \quad$ (2020) ISSN 0016-7061. https://doi.org/10.1016/j.geoderma.2019.113988

5. Y. Fu, G. Li, T. Zheng, Y. Zhao, M. Yang, Catena, Fragmentation of soil aggregates induced by secondary raindrop splash erosion, 185, 104342 (2020), ISSN 0341-8162. https://doi.org/10.1016/j.catena.2019.104342

6. T. Li, Y. Zhang, S. Bei, X. Li, S. Reinsch, H. Zhang, J. Zhang, Catena, Contrasting impacts of manure and inorganic fertilizer applications for nine years on soil organic carbon and its labile fractions in bulk soil and soil aggregates, 194, 104739 (2020), ISSN 0341-8162. https://doi.org/10.1016/j.catena.2020.104739

7. Y. Yan, X. Wang, Z. Guo, J. Chen, X. Xin, D.i Xu, R. Yan, B. Chen, L. Xu, Catena, Influence of wind erosion on dry aggregate size distribution and nutrients in three steppe soils in northern China, 170, 159-168 (2018) ISSN 0341-8162. https://doi.org/10.1016/j.catena.2018.06.013

8. N. Shahabinejad, M. Mahmoodabadi, A. Jalalian, E. Chavoshi, Geoderma, The fractionation of soil aggregates associated with primary particles influencing wind erosion rates in arid to semiarid environments, 356, 113936 (2019) ISSN 0016-7061. https://doi.org/10.1016/j.geoderma.2019.113936 
9. L. Guo, J. Shen, B. Li, Q. Li, C. Wang, Y. Guan, L. P. D'Acqui, Y. Luo, Q. Tao, Q. $\mathrm{Xu}, \mathrm{H}$. Li, J. Yang, X. Tang, Science of The Total Environment, Impacts of agricultural land use change on soil aggregate stability and physical protection of

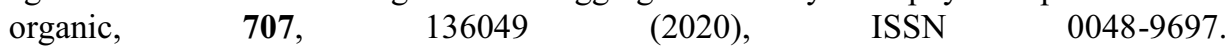
https://doi.org/10.1016/j.scitotenv.2019.136049

10. J. Cooper, I. Greenberg, B. Ludwig, L. Hippich, D. Fischer, B. Glaser, M. Kaiser, Agriculture, Ecosystems \& Environment, Effect of biochar and compost on soil properties and organic matter in aggregate size fractions under field conditions, 295, 106882 (2020) ISSN 0167-8809. https://doi.org/10.1016/j.agee.2020.106882

11. B. Xue, L. Huang, Y. Huang, Z. Yin, X. Li, J. Lu, Catena, Effects of organic carbon and iron oxides on soil aggregate stability under different tillage systems in a rice-rape cropping system, 177, 1-12 (2019) ISSN 0341-8162. https://doi.org/10.1016/j.catena.2019.01.035

12. Y. M. Awad, E. Blagodatskaya, Y. S. Ok, Y. Kuzyakov, European Journal of Soil Science, Effects of polyacrylamide, biopolymer and biochar on the decomposition of 14C-labelled maize residues and on their stabilization in soil aggregates, 64(4), 488499 (2013). DOI: 10.1111/ejss.12034

13. B. Kurmi, A. Jyoti Nath, R. Lal, A. Kumar Das, Science of The Total Environment, Water stable aggregates and the associated active and recalcitrant carbon in soil under rubber plantation, $\mathbf{7 0 3}, \quad 135498 \quad$ (2020) ISSN $\quad$ 0048-9697. https://doi.org/10.1016/j.scitotenv.2019.135498

14. Q. Zhang, Z. Du, Y. Lou, X. He, Catena, A one-year short-term biochar application improved carbon accumulation in large macroaggregate fractions, 127, 26-31 (2015) https://doi.org/10.1016/j.catena.2014.12.009

15. D. Biesgen, K. Frindte, S. Maarastawi, C. Knief, Clay content modulates differences in bacterial community structure in soil aggregates of different size, Geoderma, 376, 114544 (2020) ISSN 0016-7061. https://doi.org/10.1016/j.geoderma.2020.114544

16. L. Gao, B. Wang, S. Li, H. Wu, X. Wu, G. Liang, D. Gong, X. Zhang, D. Cai, A. Degré, Catena, Soil wet aggregate distribution and pore size distribution under different tillage systems after 16 years in the Loess Plateau of China, 173, 38-47 (2019) ISSN 0341-8162. https://doi.org/10.1016/j.catena.2018.09.043

17. S. Vladychenskii, V. M. Telesnina, K. A. Rumyantseva, T. A. Chalaya, Eurasian Soil Science, Organic matter and biological activity of postagrogenic soils in the southern taiga using the example of Kostroma oblast, 46, 518-529 (2013) https://doi.org/10.1134/S1064229313050141

18. R. Bu, T. Ren, M. Lei, Bo Liu, X. Li, R. Cong, Y. Zhang, J. Lu, Agriculture, Ecosystems \& Environment, Tillage and straw-returning practices effect on soil dissolved organic matter, aggregate fraction and bacteria community under rice-ricerapeseed rotation system, 287, $106681 \quad$ (2020) ISSN 0167-8809. https://doi.org/10.1016/j.agee.2019.106681

19. X. Xu, S. Schaeffer, Z. Sun, J. Zhang, T. An, J. Wang, Carbon stabilization in aggregate fractions responds to straw input levels under varied soil fertility levels, Soil and Tillage Research, 199, $104593 \quad$ (2020) ISSN 0167-1987 https://doi.org/10.1016/j.still.2020.104593

20. A. Mustafa, X. Minggang, S. A. A. Shah, M. M. Abrar, S. Nan, W. Baoren, C. Zejiang, Q. Saeed, M. Naveed, K. Mehmood, A. Núñez-Delgado, Journal of Environmental Management, Soil aggregation and soil aggregate stability regulate organic carbon and 
nitrogen storage in a red soil of southern China, 270, 110894 (2020) ISSN 0301-4797 https://doi.org/10.1016/j.jenvman.2020.110894

21. R. Huang, D. Tian, J. Liu, S. Lv, X. He, M. Gao, Agriculture, Ecosystems \& Environment, Responses of soil carbon pool and soil aggregates associated organic carbon to straw and straw-derived biochar addition in a dryland cropping mesocosm $\begin{array}{lllll}\text { system, } & \mathbf{2 6 5}, & 576-586 & \text { (2018) } & \text { ISSN }\end{array}$ https://doi.org/10.1016/j.agee.2018.07.013 